\title{
Exploring the Impact of a Task-Based Faculty Development Certificate Program
}

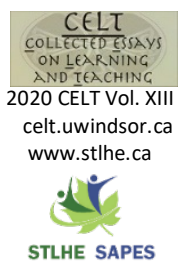

\author{
Shannon E. Rushe, Diane J. Salter \\ St. Georges University
}

Faculty Development programs aim to improve the knowledge, attitudes and behaviours of teaching faculty with the goal of enhancing the student learning environment. This article describes a two-year research project that explored the impact of a task-based faculty development certificate program. Attitudinal and behavioural changes were assessed by using both quantitative and qualitative measures. Participants' approaches to teaching were measured by administration of an established pre-and post-participation inventory to provide quantitative data; qualitative analysis was conducted in a review of the written post-session tasks and reflection papers. Results suggest that participation in this certificate contributed to attitudinal and behavioural change with a shift from teacher focused/content-based approaches towards student focused/learner centered approaches to teaching.

Les programmes de perfectionnement du corps professoral visent à améliorer la connaissance, l'attitude et le comportement des enseignants de manière à fournir aux étudiants un meilleur milieu d'apprentissage. Dans cet article, nous présentons un projet de recherche qui a duré deux ans et qui portait sur l'incidence d'un programme de certificat en perfectionnement du corps professoral axé sur les tâches. On évaluait les changements dans l'attitude et dans le comportement au moyen d'outils quantitatifs et qualitatifs. On prenait la mesure des approches enseignantes des participants au moyen de relevés an amont et en aval de la participation de manière à recueillir des données quantitatives. Quant à l'analyse qualitative, elle provenait du matériel écrit, soit les tâches d'après-séance et les travaux réflexifs. Les résultats indiquent que la participation à ce programme de certificat a engendré des changements dans l'attitude et le comportement des professeurs, lesquels sont passés d'une approche axée sur l'enseignant et le contenu à une approche axée sur l'étudiant ou l'apprenant.

$\mathrm{I}_{\mathrm{f}}^{\mathrm{n}}$ this study, the learners were cross-disciplinary faculty who participated in a professional development certificate program entitled "Basics and Beyond". Our task-based faculty development program included core sessions on foundational principles as well as a wide range of elective sessions related to teaching and learning (Salter, Rushe and Jacobs, 2019). Findings in this paper are based on a two-year research project conducted at St. George's University (SGU) in Grenada. The project was approved by the Institutional Ethics Review Board. Our program was designed to serve multidisciplinary, international faculty at SGU. Like other institutions, many of our faculty enter the profession of teaching at the university level with content expertise but little prior experience in teaching, lesson planning or course design. Based on a needs assessment with oncampus stakeholders, many faculty felt that the goal of their teaching was to impart knowledge through didactic instruction and that, without prior pedagogical guidance, creating lessons which required active student involvement was challenging.

Research strongly supports the view that active learning is more likely to promote deep versus surface learning (Biggs and Tang, 2005; Wilson and Fowler, 2005; and Chickering and Gamson, 1991). 
This type of active learning is achieved by planning lessons that include learning tasks that require students to interact with the content (Laurillard, 2002; Littlejohn, 2003, Salter et al., 2004; and Vella, 2000). Therefore, our goal was to create a program that engaged faculty in active learning activities and to subsequently be able to implement active learning principles in their own courses. In the design and delivery of the "Basics and Beyond" program we modeled an active learning, task-based approach which required participants to design similarly engaging courses and learning tasks for their students.

\section{The Basics and Beyond Program}

Our program was designed with an emphasis on reflection and application through post-session tasks and associated deliverables. As with many students, our faculty (students within the certificate program) were motivated by these tasks to engage deeply with the material in an active fashion. The in-class workshop sessions were designed to introduce topics, engage participants in various activities and discussions, and empower faculty to apply what they had learned to their courses and interactions with students. Post-session tasks, following each in-class workshop, allowed faculty the opportunity to immediately apply what they learned in sessions to their teaching practice. Based on feedback recommendations from a needs assessment of oncampus stakeholders, this program was designed to have flexible entry and flexible completion timelines. Sessions were not sequential; faculty chose to attend sessions that were timely and relevant to their current needs and context.

In the first two years of the program, three certificates in Teaching and Learning were offered: Scholarly Foundations, Research, and Leadership. Each certificate required faculty to attend eight sessions (four core and four elective), complete the associated post-session tasks for each session, write a reflective essay, and attend a consultation with a member of the faculty development team. On average a certificate represented a minimum of 30 hours of professional development work. The four core sessions in each certificate were:

1. Scholarly Foundations in Teaching and Learning Certificate:

- Planning Your Class for Active Learning

- Aligning Learning Outcomes, Activities, and Assessments

- Approaches to Teaching that Enhance Students' Approaches to Learning

- Assessment for Learning

2. Research in Teaching and Learning Certificate:

- Being a Mindful Practitioner

- Educational Research Methods

- Educational Research Ethics

- Publishing Your Research on Teaching and Learning

3. Leadership in Teaching and Learning Certificate:

- Communities of Practice

- Leading Curriculum Change Initiatives

- Coaching and Mentoring

- Distributed Leadership in Teaching and Learning

Electives were an important component of the program, which allowed a range of new topics to be added on a regular basis. To help build capacity, visiting professors and campus experts were invited to lead elective sessions within the certificate program. External session leaders worked with the Faculty Development team to design their sessions and post-session tasks. New electives were added each term based on the needs of the community and the expertise on campus. Each semester, multiple electives were offered for faculty to choose from.

Some of the elective sessions offered include: Small Group Facilitation Skills, Inclusive Teaching: Universal Design, Designing Rubrics to Enhance Learning and Feedback, Effective use of Panopto (Lecture Capture Software), Creating Your Power 
Point Slides with Your Students in Mind, Mindfulness in Teaching, Learning and Everyday Life, Fishbowl: A Technique for Building Discussion Skills, Intersectionality and the Learning Experience, Four Evidence-based Practices for Teaching in Higher Education, Providing Evidence of Teaching Through Teaching Portfolios, Preparing a Teaching Philosophy Statement, and Embedding 3D Graphics into your Lectures.

Both sessions and electives included postsession activities to provide an opportunity for faculty to implement the ideas and strategies presented in the face-to-face session. The post-session tasks required application of the content, concepts and strategies to promote deep learning. Completed tasks were submitted, providing evidence that the faculty had attempted to apply the strategies in their own teaching context.

Some examples of post-session tasks include: creating a table showing alignment of learning outcomes, activities and assessments, completing an Ethics Review Board application for an educational research project, reflecting on their experiences as a leader, reviewing their power point slides to identify which images in their PowerPoint slides would be better as 3D graphics, drafting a teaching philosophy statement, and trying out new active learning techniques (such as the fishbowl activity) in their course and reflecting on the process. Detailed examples of completed post-sessions are included later in this paper.

\section{How Do We Measure Impact?}

Measuring the impact of any professional development program is complex, therefore we took a multi-faceted approach in our evaluation. We assessed impact using quantitative and qualitative measures including attendance data, pre/post Approaches to Teaching Inventory scores, feedback surveys at the end of each term, a thematic analysis of the reflective essays and assessment of the postsession tasks. Using multiple forms of assessment at various points in time, we hoped to assess both immediate and longer-term impact of the program.
Upon registering for the program, faculty were invited to participate in the research project. Participation was optional and not required in order to enrol in the program. The consent form stated that required components of the program (ATI scores, reflections and post-session tasks) would be used for research purposes and informed participants they could withdraw from the research project without any impact to their progress within the program.

\section{Results}

\section{Attendance Numbers}

In the two-year research period, 163 participants registered in the program, with a total attendance of 1790 in 112 workshops. Eighty-two certificates were awarded: 46 Scholarly Teaching certificates, 19 Research certificates and 17 Leadership certificates.

\section{ATI Score}

Participants completed the Approaches to Teaching Inventory (ATI) as a pre and post measure of their approach to teaching. ATI scores were calculated according to the scoring procedure developed by Prosser and Trigwell (1999) and categorized into either a Conceptual Change/Student Focused (CCSF) or an Information Transfer/Teaching Focused (ITTF) approach depending on which category had the highest score. Participants whose scores in each category differed by six points or less were categorized as having a balanced approach. In the pre-participation ATI inventory $32 \%$ of participants were categorized as Balanced (B), 22\% as Information Transmission/Teaching Focused (ITTF) and $46 \%$ as Conceptual Change/Student Focused (CCSF). In the post-test inventory scores, $32 \%$ were categorized as Balanced, $4 \%$ as Information Transmission/Teaching Focused (ITTF) and 64\% Conceptual Change/Student Focused (CCSF). The percentage of teachers in the Balanced range stayed the same, however, the overall group change was a strong shift in approach from Information Transfer/Teaching Focused to Conceptual Change/Student Focused. 


\section{Table 1}

The percentage of participants before and after the Scholarly Foundations certificate who were categorized as either Conceptual Change/Student Focused (CCCF), Information Transmission/Teaching Focused (ITTF), or Balanced.

\begin{tabular}{ccc}
\hline Category & Pre Test & Post Test \\
\hline CCSF & $45.5 \%$ & $63.8 \%$ \\
Balanced & $31.8 \%$ & $31.8 \%$ \\
ITTF & $22.7 \%$ & $4.5 \%$ \\
\hline
\end{tabular}

\section{Reflection Times}

The shift towards a learner-centered approach is also apparent in the inductive thematic analysis of the completed reflective papers. Submission of a reflective paper was a required component for completion of a certificate. For the purposes of this project, 29 reflective papers were analyzed based on the number of papers submitted by the time the analysis began. Analysis of the reflective papers demonstrated six emerging themes: Growth Mindset, Professional Identity Formation, Transformation of Approaches to Teaching, Application of Strategies, Thinking about the Learners, and the Benefits of the Program. The most frequently occurring themes in the reflective essays were:

1. Behavioural changes through the application of new strategies;

2. An appreciation for the program as an experience which enhanced their teaching and learning abilities; and

3. Expressing a growth mindset for students and the participant's own professional development.

In the reflection essays, faculty most often spoke about the ways they had applied the ideas and strategies presented in the sessions. Two faculty spoke about applying the concept of constructive alignment saying the session "improved my role as an educator with the design, implementation, analysis and dissemination of educational outcomes and objective based lectures" and another stating "I have learnt about constructive alignment and how it is a crucial aspect in learning - it has allowed me to choose the correct activities and assessments for the appropriate outcomes and vice versa." Many faculty described how following the sessions they included various new strategies into their teaching, "I have incorporated active learning in the following methods: think-pair-share, discuss medical history questions and make diagnostic plans, use 'tinyurls' to share scholarly articles and controversies and throwing around a stuffed animal to answer the questions that I ask in class." Others wrote "I created rubrics, made a lesson plan, wrote learning outcomes and so much more" and "I have started writing lectures with learning objectives and then when I write my exams I take each learning objective and focus a question around it." These examples show self-reports of faculty changing their behaviours in the classroom as a result of their participation in the certificate program.

The second most frequent theme in the reflection essays was the benefit(s) of the certificate program. One faculty member wrote about the timeliness of the sessions stating, "I think that our program and faculty benefitted greatly from this workshop and it happened at the perfect time since we were also in the process of revisiting our curriculum." An early career faculty member said, "When I started the program, I had not begun teaching yet, however it really seemed to develop me professionally and personally. It gave me confidence to see what common difficulties were encountered by teachers and to prepare for them and see them coming." Another faculty member stated that they incorporated most of what they learned into their teaching duties and saw a change in feedback from students saying, "I have already seen some changes in my feedback which is mostly now strongly positive." One faculty member wrote about the benefits of the design of the program: "The classes were just the right size to allow for active participation and quick 
feedback, it made it easy to form small groups and have quick discussions. The classes were short; however, they were informative and always left you wanting to incorporate some of the skills that were explained."

Statements that reflected a growth mindset for faculty and/or students were the third most common theme in the reflection essays. One faculty member used the following metaphor to describe their interest in continuing to feed their knowledge: "The first session was on small group facilitation and the session had me engrossed on how I can improve. In essence, I was the fish and the knowledge was the worm, and since then I kept going to [the program] to get the worm." The program directors were happy to see how many faculty were excited about continuing to learn through the program with statements such as, "I believe that the opportunity we have to further our knowledge in the area of teaching and scholarship is very valuable and I think that may more of us should go through the program" and "I have learned a lot and am looking forward to continual educational enhancement as I pursue the other certificates." Faculty recognized the ongoing learning journey that teaching requires: "The one thing I have learned being involved in so many pedagogy initiatives is that I do not know nearly enough...Going through these modules I realize more and more how much there is to learn to be an effective educator." Another faculty member detailed the areas that they still need to focus on writing, "The parts of the Basics and Beyond course work that I learned, I try to incorporate into my teaching but still struggle with are the need to relay information and incorporating active learning. These struggles are not necessarily a negative experience but rather a work in progress."

Many faculty made statements about how the sessions transformed their approaches to teaching such as, "My new objective is engage the students, to make them understand the concepts, to ask questions, to rationalize and to leave the classroom with an inner satisfaction that they understood the material" and "the modules on active learning techniques for small and large groups were very helpful. I am now able to engage students more during laboratory and lecture sessions. Consequently, the evaluation from students has greatly improved." One experienced faculty member attending the sessions said, "So here I am, after several years of teaching, officially being taught how to teach, learning alongside many of my former students. It has been a great and sometimes amusing experience, for which I am grateful. I am now more concerned about my students learning than about my teaching", showing evidence that they have shifted their thinking away from a teacher focused approach to one that centres around students' learning. Another wrote about how their teaching philosophy had changed: "After attending this course, I will be able to bring multiple changes to my teaching and facilitation style. Before attending this session, my teaching philosophy was just to teach, I was not thinking about student's mental learning capacity or capability, just wondering about their grades. After being a part of this course, I realize that teaching is not just putting or imposing things on students, rather it's a structured method of learning strategies that would help students in their educational journey."

As stated above, faculty most often spoke about how they had applied what they learned in this program; however, many also wrote about their intention to apply strategies in the future. One faculty gave specific examples stating " $[\mathrm{t}]$ he concepts I will attempt to employ in my future lectures would be the attention grabbers placed throughout the lecture. These will take the form of multiple-choice questions which related to a topic that has just been covered. This will be a good way to wake the audience up...I will also attempt to employ the concept of pre and post class tasks which are great ways to encourage independent learning." Another faculty member wrote, "I will continue to review and adapt the materials and assessments in my courses to meet the needs of all my students, I will continue to pay attention to aligning course learning outcomes, lecture and program outcomes. I plan to use a combination of formative and summative assessment to bring out the best performance from each student and I will embrace technology in my lectures and labs 
(I did not really embrace technology optimally previously)." One participant started thinking about their leadership style after a session by "immediately drawing up a concept map on how to have more of a shared governance in the department. Using some of the tools used in the session I looked at areas I am responsible for but need faculty input and assistance, so it becomes less 'top down'." While the intention to apply strategies is not evidence of changed behaviour, these statements highlight how participation in this program encouraged faculty to think about the strategies and behaviours they could employ in their future courses, research and leadership roles.

\section{Post-Session Tasks}

The post-session tasks were assessed for completeness and application of ideas and strategies presented. During the final consultation with a member of the faculty development team, feedback was provided to faculty on their post-session tasks. Feedback on post-session tasks was also provided throughout the certificate program when requested by the participant. Below are examples of tasks that were completed by faculty providing evidence that they had achieved the session outcomes, or at minimum, had completed a first attempt in implementing what was discussed in sessions. One important aspect of our approach is in creating tasks that are relevant to specific teaching challenges and providing templates as guiding tools that faculty can adapt for their own context. The following two examples show descriptions of the challenge, the tasks and the faculty's response to the task.

\section{Example One}

\section{The Challenge}

In the certificate course "Effective Use of Technology to Create Instructional Videos", faculty were required to create videos as directed learning activities for students to streamline some of their lecture material in specific courses. The challenge was both pedagogical and technological. How would they create a video that was interesting and engaging, and not just a recording of a didactic lecture? This activity leveraged a desire to learn a technical skill with learning more about pedagogical best practices.

\section{The Task}

After attending the session, faculty were required to create a storyboard for a directed learning activity video that would be viewed by their students asynchronously. The storyboard template required faculty to identify what the faculty member would say, what the students would see and what the students would do during each segment of the video. Some faculty listed talking points, but others wrote out a script for what they would say. Faculty could include actual images in the template, or just describe what students would see. In the 'what they do' column, faculty could put what they expected students to do as a result of the video, or what they would do while watching the video (e.g. listen, answer a multiple choice question embedded in the video, etc.).

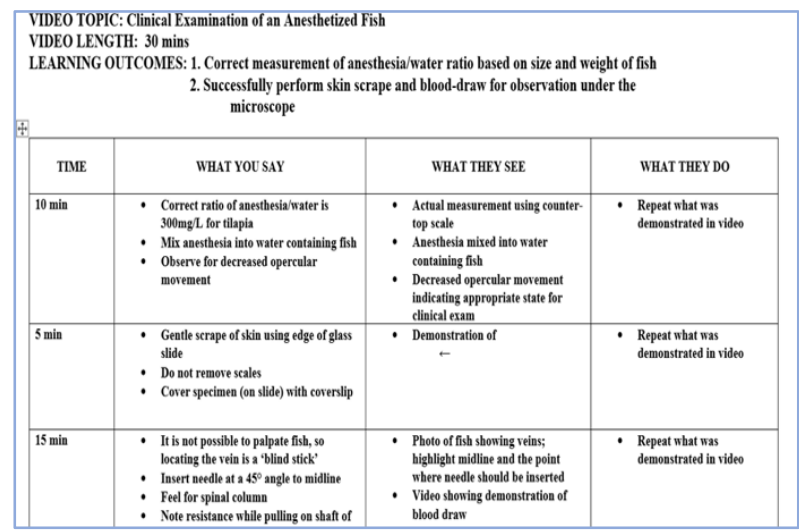

Figure 1

An example of a completed storyboard template.

\section{Example Two}

\section{The Challenge}

Faculty are often put into positions of leadership without opportunities to think about or plan for the type of leader that they would want to be. How would they describe the type of leader they want to be? 
Which leadership styles or strategies would they employ?

\section{The Task}

In this session, faculty were asked to draw a metaphor for leadership. This post-session task asked faculty to select one of the metaphors for leadership drawn in the face-to-face session and discuss why it resonated with them the most.

\section{The Response}

"I liked the face metaphor the most, as it really summed up perfectly how task-dependent leadership and cooperation can be. If the task is to gather sensory information, the leaders are the eyes, ears, and nose, but other parts of the face must work together, like eye muscles pointing the eyes in the right direction. If the task is to exhibit emotion, all the muscles must coordinate with the brain and our cognitive templates of memory and emotion. If the task is to hide an emotion, the muscles, brain, and the eyes reading the other person must also occur. The leader is not clearly one part of the face at any one time but changes relative to the task."

\section{Feedback Survey}

A feedback survey was sent to participants at the end of the first year of the program to assess the reaction to and impact of the program. The response rate was $20 \%$. Faculty had positive responses with $94 \%$ of respondents stating that participation in the certificate program was useful in their work as an educator and contributed to their ability to engage students in learning. All the respondents indicated that the post-session tasks helped develop their ability to use the strategies and implement new approaches to curriculum design and teaching. Self-report measures are not always a true indicator of changes in attitudes or behaviour, but these responses provided evidence to our team that faculty were satisfied with the program and found the post-session tasks valuable despite being time consuming.
Many participants highlighted the importance of the post-session tasks in their reflection essays and the feedback survey. One faculty member stated that the post-session tasks "were a great addition to the overall learning experience of the program because it encouraged me to review all that I had learned from the session. It helped keep the material fresh in my mind without me having to go back to it on my own." Faculty not only applied what they learned to their own courses, but often shared the ideas with their colleagues saying "some of what I have learned, I have shared with other professional colleagues, who were most impressed and also incorporated some into their teaching".

Despite the additional time it takes to complete the tasks faculty "found them to be very relevant and useful. I began applying the concepts and exercises to my course and planned some of my classes at the same time." One faculty stated, "honestly, I had reservations about having to do the post session tasks for all eight sessions. However, once I did the first one and realized that it was practical, meaning that I could use it for my course, I was excited to do them even though they were time consuming."

\section{Next Steps for the Program}

As the program continues to grow and new needs are presented, the faculty development team plans to create new certificates to continue to support faculty. Two additional certificates have been created since the launch of this program. The first is in Online Teaching and Learning with core session topics: Building a Shared Understanding of Online Learning, Communication and Creating Community Online, Authentic Assessment and Online Content Creation. This certificate was created in collaboration with our Office of Online Innovation and campus experts in online teaching. The second newly developed certificate is in Diversity \& Inclusion in Teaching and Learning with the following core sessions: Inclusive Teaching Universal Classroom Design, Safe Zone Training, Linguistic Differences and Critical Multiculturalism. The team will continue to add 
certificates at the request of faculty and to address the changing needs of the institution. The delivery of new certificates encourages faculty to continue engaging in the certificate program. The achievement of a certificate is an important milestone but does not mean the professional learning journey is complete. While mere participation does not mean that faculty are changing their teaching practice, their continued interest and requests for new certificates and electives suggests that faculty are motivated to engage in continuing professional development.

Given the consistent growth in participants within the program, the team plans to devise a strategy to ensure that faculty will receive consistent and timely feedback on their post-session tasks. The value of the post-session tasks is highlighted by many of the comments made by faculty in the reflection essays and the feedback survey. As a result, it is important to ensure that learning through the tasks is maximized by providing timely and specific feedback. Another opportunity for timely feedback is the development of a community of Peer Teaching Observers. This group will be given guidance on how to observe and provide constructive feedback to their fellow faculty members to assist in requests for teaching observations and to enrich the experience for all those involved by creating a community of practice. Pre and post teaching observations may provide additional evidence of changes in attitudes and behaviours as a result of participation in the certificate program in the future.

\section{Conclusion}

This project explored the impact of the "Basics and Beyond" program in various ways. The change in ATI scores following participation in the program shows evidence of a shift in attitudes about teaching from an information transmission/teaching focused approach to a conceptual change/student focused approach. Analysis of the reflection papers highlights new attitudes towards teaching as well as behavioural changes; comments showed that faculty were now thinking intentionally about the learner and about how they could implement new strategies to create opportunities for active learning in their classes. Assessment of the post-session tasks show at minimum a first attempt to implement the ideas and theories discussed in the session while many completed tasks also showed implementation and reflection. The various measures used illustrate attitudinal and behavioural changes in our participants following completion of one, or multiple, certificates.

Participants consistently highlighted the value of the post-session tasks in creating change in their approaches to teaching. Active learning is highly encouraged in teaching and learning workshops so as educational developers it is important that we apply the same pedagogical principles within our own programs. We feel this requires creating opportunities for faculty to immediately apply knowledge gained in workshops or other teaching and learning activities to their own context. Post-session tasks create the opportunity to achieve this goal and encourage meaningful change in course design and delivery. Incorporating value-adding, relevant and timely postsession tasks into our faculty development programs is one way that we can enrich the learning environment. Many participants in our program commented on the benefit of the active learning they experienced during completion of their certificate(s). In conclusion, it is difficult to assess the impact or attribute changes in behaviour to programs such as the one presented above but our team believes that the combination of data suggests that a task-based faculty development program can create change in teaching attitudes and behaviours that will subsequently enhance the student learning environment.

\section{References}

Biggs, J. \& Tang, C. (2005). Teaching for quality learning at university. UK: McGraw-Hill Education.

Chickering, Arthur \& Gamson, Zelda (1991). Seven principles of good practice in undergraduate 
education. New Directions for Teaching and Learning, (47): 63-69.

Laurillard, D. (2002). Rethinking university teaching: $A$ conversational framework for the effective use of learning technologies. New York: Routledge.

Littlejohn, A. (2003). Reusing online resources. Kogan Page, London.

Prosser, M., \& Trigwell, K. (1999). Understanding learning and teaching: The experience in higher education. Buckingham, UK: Open University Press.

Salter, D., Richards, L., \& Carey, T. (2004). The 'T5' design model: An instructional design model to support the integration of online and campus based learning. Educational Media International, $\quad 41(3), \quad 207-217$. doi:10.1080/09523980410001680824

Salter, D. J., Rushe, S. E., \& Jacobs, G. (2019). Basics and Beyond: Faculty Development as a Professional Learning Journey. Journal on Centers for Teaching and Learning, 11.

Vella, J (2000). Taking Learning to Task. San Francisco: Jossey-Bass.

Wilson, K., \& Fowler, J. (2005). Assessing the impact of learning environments on students' approaches to learning: Comparing conventional and action learning designs. Assessment \& Evaluation in Higher Education, 30(1), 87-101.

\section{Biographies}

Shannon Rushe (M.Ed) is a former Educational Developer at St. George's University and currently a Learning Specialist and Program Coordinator at the University of Guelph.

Diane Salter's leadership roles in higher education include Director of Faculty Development, SGU, Grenada; VPTL, KPU, BC ; Dean Curriculum and
Faculty Development, Sheridan, Ontario. Diane, based in BC, consults internationally. 